\title{
Selection of the Friction Model for Numerical Analyses of the Impact of Longitudinal Vibration on Stick-Slip Movement
}

\author{
Marta Rybkiewicz ${ }^{1 *}$, Mariusz Leus ${ }^{1}$ \\ 1 Faculty of Mechanical Engineering and Mechatronics, West Pomeranian University of Technology in Szczecin, \\ ul. Piastów 19, 70-310 Szczecin, Poland \\ * Corresponding author's email: marta.rybkiewicz@zut.edu.pl
}

\begin{abstract}
The purpose of the experimental and numerical tests presented in this paper was to indicate a friction model suitable for simulation analyses of the impact of longitudinal tangential vibrations on stick-slip movement in sliding motion. The vibration parallel to the shift direction are forced in the contact zone of a shifted body and the base. They can cause partial or total reduction of the stick-slip phenomenon or even reduce the value of necessary drive force. The time characteristics of drive force were determined experimentally and in simulation for two cases, i.e. at a motionless or vibrating base. Simulation analyses were carried out in accordance with the described computational procedures implemented in Matlab-Simulink environment. Four models of friction were tested in the presented studies: Dahl, Karnopp, Reset Integrator and LuGre. Experimental tests were carried out on a specially designed tests stand. The Root Mean Square Error (RMSE) was used to compare the results of numerical calculations with results of experimental tests. The performed qualitative assessment and the determined RMSE values indicated that the LuGre and the Reset Integrator models ensure he best consistency of model and experimental time characteristics of the driving force.
\end{abstract}

Keywords: reduction of stick-slip, friction models, longitudinal tangential vibrations.

\section{INTRODUCTION}

Friction is a complex phenomenon that commonly occurs in nature and has a significant impact on the work of many mechanical devices. Therefore, at their design stage, it is extremally important to select the appropriate friction model that reproduces all relevant friction phenomenon in this case and ensure sufficient compliance of the computational results with actuality. Friction models available in literature explain different experimentally observed friction phenomena, such as: static friction, break-away force and dynamic friction [1, 2, 3], pre-sliding displacement [4], Stribeck effect $[5,6]$, hysteretic effects $[7,8]$ or stick-slip movement $[9,10]$. Each friction model has strengths and weaknesses, but its usefulness depends on the specific physical and operational conditions [11]. This paper focuses on selecting the appropriate friction model to the computational analyses of stick-slip phenomenon and of the impact of tangential longitudinal vibrations on it. The complexity of the analyzed phenomenon requires the adoption of a friction model that reflects alike the stick-slip vibrations, the stages of their elimination and the subsequent effect of a decrease in friction force. Therefore, the selected model has to describe particular friction phenomena e.g. presliding displacement or Stribeck effect.

The appearance of self-excited relaxation vibrations i.e. stick-slip movement is an undesirable phenomenon that hinders the work of machines, reduces the performance and the safety of operation in a wide range of engineering applications $[12,13]$. In particular, the stick-slip phenomenon causes uneven sliding movement and reduces positioning accuracy of moving units of mechanical systems e.g. in machine tools or manipulators $[14,15,16]$. Stick-slip vibration is also common in the drilling processes in the oil 
and gas industry. This is an example of torsional vibration with apparent detrimental effects on the drilling process $[13,17]$. This movement causes premature wear of drilling tools, which considerably reduces the quality of drilled shafts $[13,18]$ and is a source of failure [19, 20]. In addition, it reduces the efficiency of drilling operations by reducing velocity of penetration [17, 21, 22]. From these reasons, it significantly increases the costs of drilling operations [23, 24]. The stickslip phenomenon is also a source of unpleasant sounds that can be heard in everyday life e.g. the creaking of hinges in the door, the squeak of the tram wheels at the bend and the squeak of chalk on the blackboard $[25,26]$.

The appearance of stick-slip vibration can be caused by an increase in friction force during standstill [16, 27], due to the large difference between the static and kinematic friction coefficient $[15,28,29,30,31]$, low sliding velocity or low drive stiffness $[32,33]$. The presence of these vibrations can be allowed provided that the amplitude of the vibration is small enough [26]. However, it is intended to eliminate them completely or at least reduce the intensity of these vibrations. There are several ways to eliminate stick-slip phenomenon in sliding motion. Good effects are obtained by using special materials for friction pair, optimizing friction surfaces microgeometry, reducing normal pressures $[6$, 25], changing sliding friction to rolling friction [16] or applying lubrication [34]. The intensive experimental tests of possibilities to eliminate stick-slip movement by introducing forced vibrations in different directions in the contact

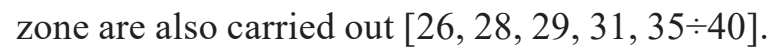

Comparative analyses of the usefulness of different friction models for simulation tests of sticksip is presented in the paper Haessig and Friedland [41], Liu et al. [42] and Pennestrì et al. [11]. The main attention in these works was focused on assessing the suitability of these models to describe stick-slip movement. However, the complexity of the issue of the impact of vibration on stick-slip phenomenon means that not all simulation models are able to reproduce them. Hence, the purpose of this paper is to assess the suitability of several selected friction models for simulation tests of the stick-slip phenomenon and its partial or total reduction under the influence of longitudinal tangential vibration forced into the friction pair contact zone. The first of the adopted models is the Dahl [43] model used by Gutowski and Leus [44] to estimate changes in friction force in sliding motion of rigid body on a vibrating base. The next three adopted friction models are: the Karnopp model [41, 45], the Reset Integrator model [41, 46] and the LuGre model [30], which were developed to describe the friction force in stick-slip movement.

The paper presents the principal mathematical relationships based on which computational models have been developed in the MatlabSimulink environment. Simulation tests were carried out on these models and next the results of them were compared with the results of experimental tests. The experimental tests were carried out on a specially constructed test stand described in paper Leus and Abrahamowicz [36]. Designated values Root Mean Square Error (RMSE) and qualitative analyses of the compliance of simulation and experimental tests allowed to assess which of the adopted friction models best reflects both the stick-slip phenomenon and its partial or total reduction under the influence of forced longitudinal vibrations.

\section{PRINCIPAL MATHEMATICAL RELATIONSHIPS. FRICTION MODELS}

A special calculation model was developed to assess the suitability of selected friction models for simulating stick-slip motion and its partial or total reduction obtained by forcing longitudinal tangential vibrations in the contact zone (Fig. 1). In this model, the upper body $A$ with mass $m$ is shifted on the support $B$ at the given velocity $v_{d}$ by a drive system with stiffness $k_{d}$. The support $B$ can be introduced into vibration at any time, on a direction parallel to the direction of the shifted body movement. The distribution of forces acting on this body is shown in Figure 2.

The equation of sliding motion of a body $A$ along the $0 x$ axis has the following form:

$$
m \ddot{x}=F_{d}-F_{f}
$$

where: $m$ - the mass, $x$ - the acceleration of the body $A, F_{d}$ - the drive force, $F_{f}$ - the friction force.

The drive force is determined from the following dependence:

$$
F_{d}=k_{d}\left(v_{d} \cdot t-x\right)
$$

where: $k_{d}$ - the stiffness coefficient of the drive system, $v_{d}-$ the drive velocity, $x-$ the displacement of the body $A, t$ - the time. 


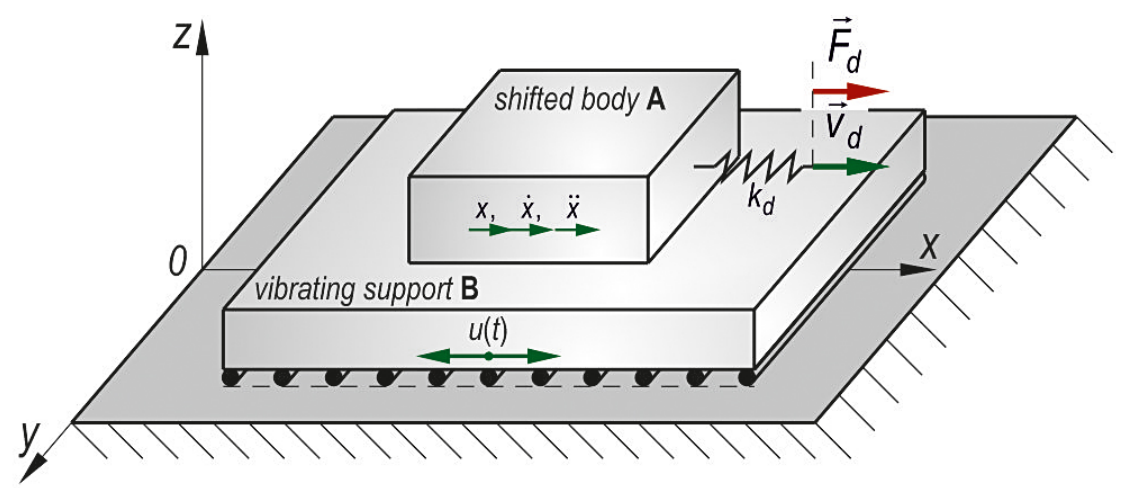

Fig. 1. The physical model of friction system - realization of sliding motion and vibration excitation

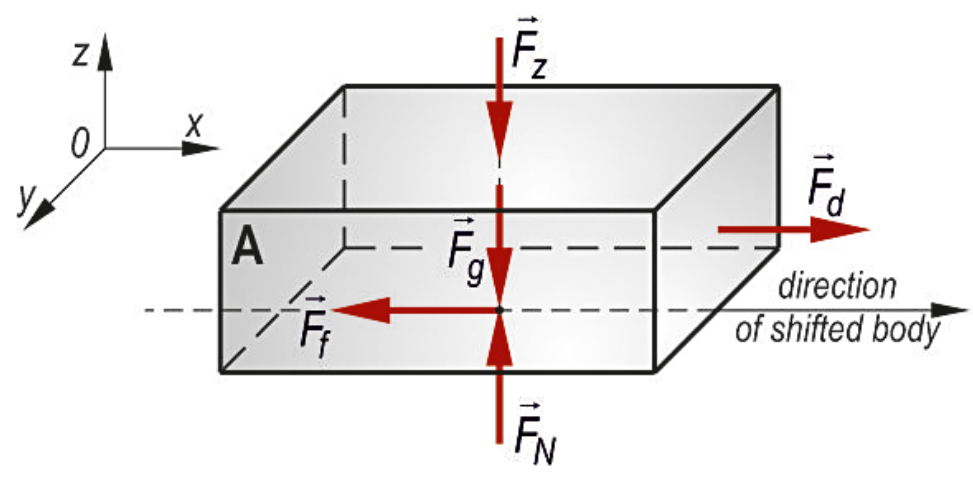

Fig. 2. The distribution of forces acting on the shifted body; $\bar{F}_{d}$-the drive force, $\bar{F}_{f}$ - the friction force, $\bar{F}_{Z}$ - the external load, $\bar{F}_{N}$ - the normal support's reaction, $\bar{F}_{g}$ - the force of gravity

The method of determining the value of the friction force depends on the adopted friction model. In this paper the calculations were based on four friction models, i.e. the Dahl model, the Karnopp model, the Reset Integrator model and the LuGre model. In developed procedures it has been also assumed that the vibrating movement of the base on which the upper body is shifted, is a harmonic movement and can be described by the relationship:

$$
u=u_{o} \cdot \sin (\omega \cdot t)
$$

where: $\omega$ - the angular velocity expressed as follows:

$$
\omega=2 \pi f
$$

where: $u_{o}$ - the amplitude, $f-$ the frequency of forced vibration.

Thus, the velocity of forced vibrations $\dot{u}$ is described by the following equation:

$$
\dot{u}=v_{a} \cdot \cos (\omega \cdot t)
$$

where: $v_{a}$ - the amplitude of forced vibration velocity.

It is a function of both basic vibration parameters: the amplitude $u_{O}$ and the frequency $f$, hence:

$$
v_{a}=u_{o} \cdot \omega
$$

\section{Dahl model}

The Dahl model [43] is commonly described as a dynamic friction model. It assumes that friction force $F_{f}$ is proportional to the elastic strain of the contact zone, which is measured in the slip plane, in the direction of the relative movement of the contacting surfaces:

$$
F_{f}=k_{t} \cdot s
$$

where: $k_{t}-$ the stiffness coefficient of contact in the tangential direction.

In the Dahl model, it is assumed that the elastic component of the contact strain can be determined from a differential relationship presented in the following form [43]:

$$
\frac{d s}{d t}=v_{r} \cdot\left[1-\frac{k_{t}}{F_{C}} \cdot \operatorname{sgn}\left(v_{r}\right) \cdot s\right]^{\kappa}
$$

The Coulomb friction force $F_{C}$ is expressed as follows:

$$
F_{C}=\mu \cdot F_{N}
$$

where: $v_{r}$ - the relative velocity of sliding body and vibrating support, $\mu-$ the coefficient of static friction. 
The $\kappa$ parameter in the above equation is a coefficient that depends on the properties of the material. Bliman [47] reports that for brittle materials the magnitude of this parameter is in the range $0<\kappa<1$, while for ductile materials it is $\kappa=1$.

The relative velocity $V_{r}$ is the superposition of the absolute velocity of the shifted body $A$ and the velocity of the vibrating support $B$. According to the markings in Figure 1, this relationship has the following form:

$$
v_{r}=\dot{x}-\dot{u}
$$

\section{Karnopp model}

The Karnopp static friction model [45, 46] distinguishes two phases of sliding friction i.e. sick and slip, which are described by separate equations as follows:

$$
F_{f}=\left\{\begin{array}{c}
\min \left(\left|F_{d}\right|, F_{S}\right) \operatorname{sgn}\left(v_{r}\right) \text { if }\left|v_{r}\right| \leq D V \\
F_{\text {slip }} \operatorname{sgn}\left(v_{r}\right) \text { if }\left|v_{r}\right|>D V
\end{array}\right.
$$

where: $F_{S}$ - the maximum static friction force, $F_{\text {slip }}$ - the sliding friction force, $D V$ - the limiting velocity of the assumed zeros velocity interval $\langle-D V, D V\rangle$.

The stick phase occurs if the relative velocity $V_{r}$ of the sliding body and support does not exceed a narrow range of zeros velocity interval. In this range, it is assumed that the relative velocity is equal to zero $\left(v_{r}=0\right)$. The friction force opposes the drive force $F_{f}=-F_{d}$ until the drive force $F_{d}$ exceeds the maximum static friction force $F_{S}$. If the driving force $F_{d}$ exceeds the value of the force $F_{S}$, the shifted body begins to accelerate. As a result, the zeros velocity interval is exceeded and the transition to slip phase occurs. In this phase, the friction force could correspond to Coulomb's friction force and be independent of the relative velocity $v_{r}[41]$.

\section{Reset Integrator model}

The friction Reset Integrator model was proposed by Heassing and Friedland [41] to improve the efficiency of numerical calculations compared to Bristle friction model. Also in this model, the contact can be presented as a single bristle, and the friction force depends on the elastic strain $s$ of the contact zone and the velocity $\dot{s}$ of this elastic deformation, whereby:

$$
\dot{s}=\left\{\begin{array}{c}
0 \text { if }\left(v_{r}<0 \text { and } s \leq-s_{0}\right) \text { or }\left(v_{r}>0 \text { and } s \geq s_{0}\right) \\
v_{r} \text { otherwise }
\end{array}\right.
$$

where: $s_{0}$ - the pre-determined maximum value of elastic strain $S$.

The value of friction force is determined as follows:

$$
F_{f}=(1+a(s)) \cdot k_{t} \cdot s+\beta \cdot \dot{s}
$$

where:

$$
a(s)=\left\{\begin{array}{l}
a \text { if }|s| \leq s_{0} \\
0 \text { otherwise }
\end{array}\right.
$$

The coefficient $a(s)$ models the phenomenon of friction increase during standstill, $\beta$ is the damping factor determined from the following dependence [41]:

$$
\beta=0.707 \cdot \sqrt{k_{t} \cdot m}
$$

When sliding occurs the velocity $\dot{s}=0$, which determines constants value of elastic strain $s$ equal maximum value $s_{0}$ and the friction force is expressed as follows:

$$
F_{f}=k_{t} \cdot s_{o} \cdot \operatorname{sgn}\left(v_{r}\right)
$$

During sticking velocity $\dot{s}=V_{r}$ and the friction force is determined by the following equation:

$$
F_{f}=(1+a) \cdot k_{t} \cdot s+\beta \cdot v_{r}
$$

\section{LuGre model}

The LuGre [30] model is a development of the Dahl model. In this model, the friction force $F_{f}$ is determined as a sum of three components referred successively to: the elastic strain $s$ of the contact, the velocity $\dot{s}$ of this elastic deformation and the relative velocity $V_{r}$ of sliding body and vibrating support:

$$
F_{f}=k_{t} \cdot s+h_{t} \cdot \dot{s}+h_{v} \cdot v_{r}
$$

where: $k_{t}$ and $h_{t}-$ the coefficients of contact stiffness and damping in the tangential direction, $h_{V}-$ the viscous damping coefficient.

The rate $\dot{s}$ of contact elastic strain is determined from the following relationship:

$$
\dot{s}=\frac{d s}{d t}=v_{r}-\frac{\left|v_{r}\right|}{g\left(v_{r}\right)} \cdot s
$$

Where:

$$
g\left(v_{r}\right)=\frac{1}{k_{t}} \cdot\left[F_{C}+\left(F_{S}-F_{C}\right) \cdot e^{-\left(v_{r} / v_{s}\right)^{2}}\right]
$$


where: $F_{S}$ - the static friction force, $v_{S}-$ the Stribeck velocity.

The value of damping coefficient $h_{t}$ of contact at tangential deflection, in case of lack of sliding, is determined from relationship [46]:

$$
h_{t}=2 \cdot \zeta \cdot \sqrt{m \cdot k_{t}}
$$

where: $\zeta$ - the critical damping.

In the case of sliding this coefficient is a function of relative velocity $V_{r}$ and it can be described as follows [46]:

$$
h_{t}\left(v_{r}\right)=h_{t} \cdot e^{-\left(v_{r} / v_{s}\right)^{2}}
$$

\section{NUMERICAL ANALYSES AND ITS EXPERIMENTAL VERIFICATION}

The numerical analyses were carried out in Matlab-Simulink environment on a specially developed computational program in which the friction models described above were used. The calculation procedures in the developed program have been grouped into several modules. Figure 3 shows a block diagram of the main computational module, and Figure 4 shows the corresponding block diagrams of individual friction models.

Developed program allows to determine the time characteristics of drive force $F_{d}$, friction force $F_{f}$ and kinematic quantities i.e. displacement $X$, velocity $\dot{X}$ and acceleration $\ddot{X}$ of the shifted body. The ode4 procedure based on the Runge-Kutta method was used to integrate the equations. The calculations were carried out for both motionless and vibrating support. The assumed initial conditions specified the zero displacement and velocity of moving body $(x=0 \mathrm{~mm}, \dot{X}=0 \mathrm{~mm} / \mathrm{s})$ at time $t=0 \mathrm{~s}$. The support vibrations were introduced after $t=10 \mathrm{~s}$ from the beginning of the movement.

Simultaneously with the numerical analyses, authors performed the experimental tests to verify the results of calculations. The experimental researches were carried out on a special test stand, which was described in detail in the paper Leus and Abrahamowicz [36]. The test stand was designed and build to determine the quantitative changes in the drive force $F_{d}$ and the friction force $F_{f}$ in sliding motion in the presence of longitudinal tangential vibrations introduced into the friction pair contact zone. The view of the mechanical part of this stand is shown in Figure 5.

The main part of this test stand is a friction pair of upper and lower specimen. The upper specimen is shifted by the drive system on the lower specimen, which rests on roller guides and can be set into vibration movement at any time using a piezoelectric vibration exciter. The system records changes in the drive force $F_{d}$, which is necessary to initiate and maintain the sliding motion of the upper specimen. This force is measured by a ring dynamometer located between the shifted upper specimen and the carrier, which is a part of the drive system. At the same time, the accelerations of both specimens along the axis of forced vibration are measured also the displacements of the upper specimen and the drive system are recorded.

In the experimental tests, as in the numerical analyses during shifting the upper specimen, the initially motionless lower specimen is set into vibration movement. The carrier moves at a

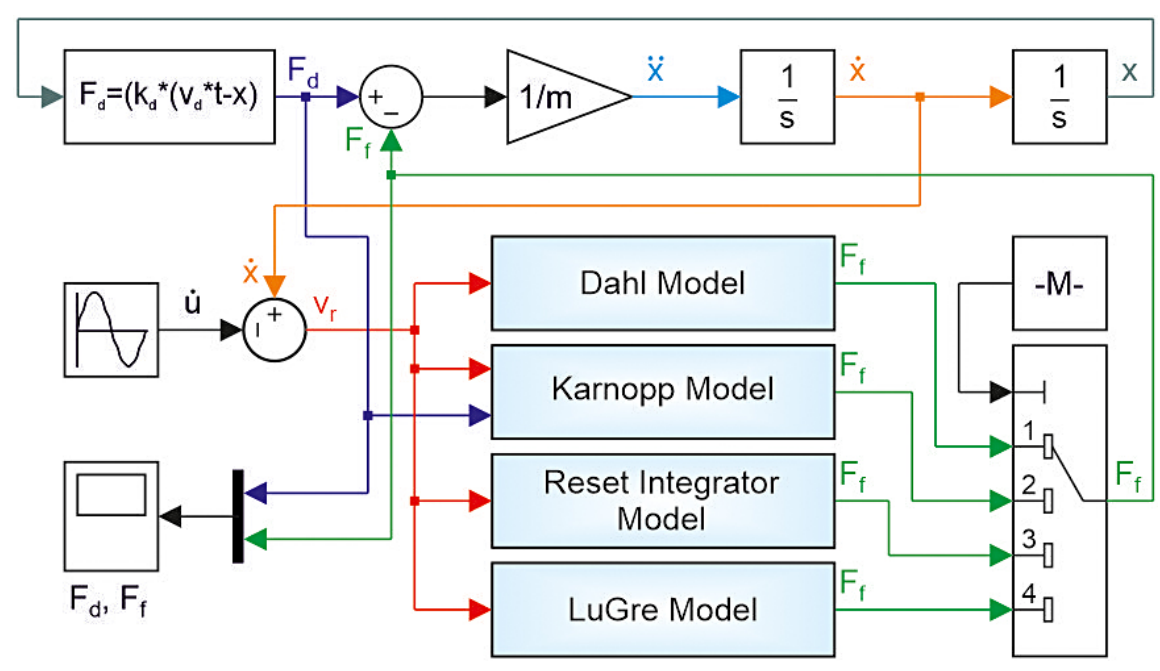

Fig. 3. The block diagram of the main computational module developed in the Matlab-Simulink environment 

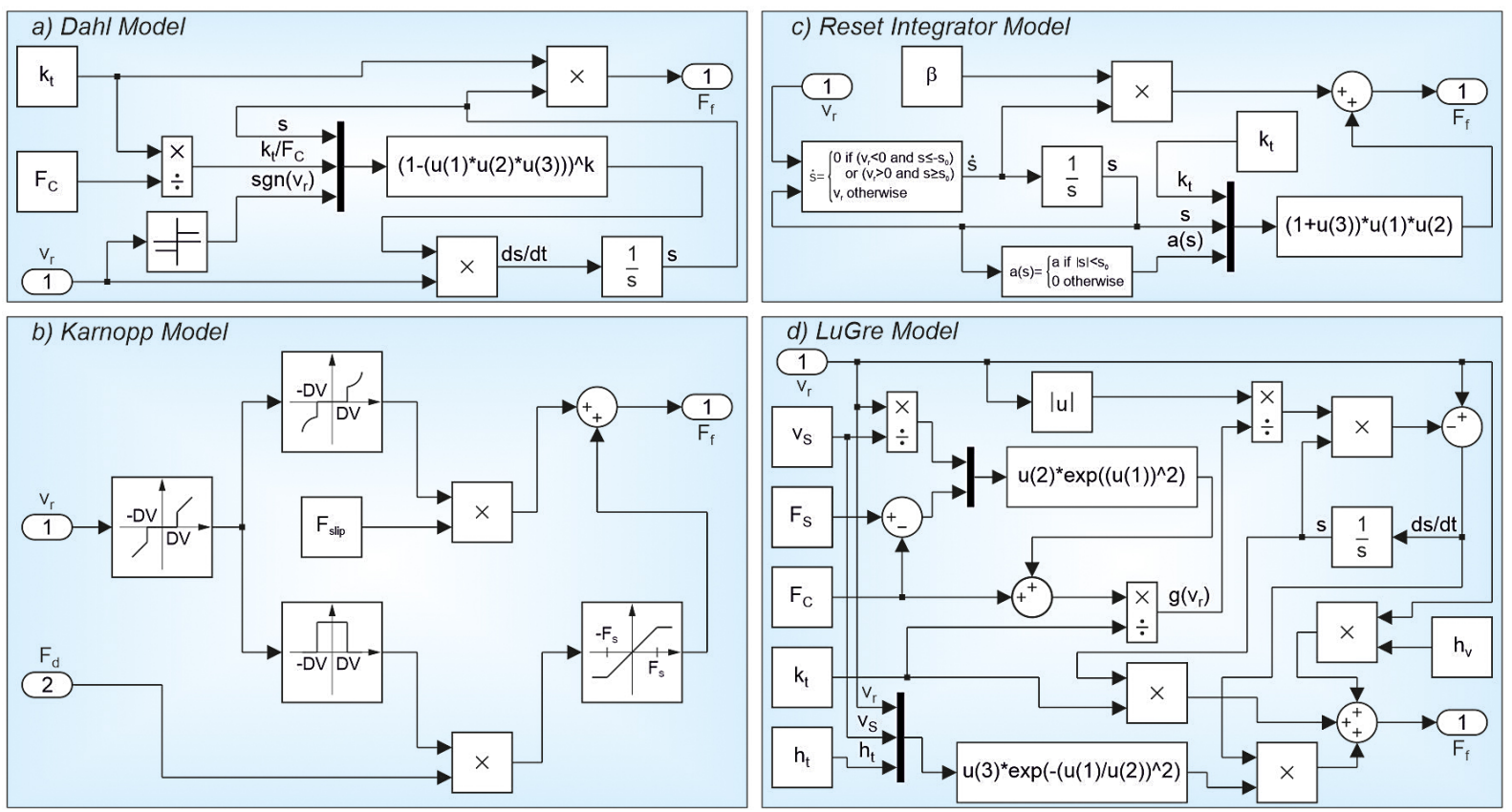

Fig. 4. The block diagram of: a) Dahl model, b) Karnopp model, c) Reset Integrator model, d) LuGre model

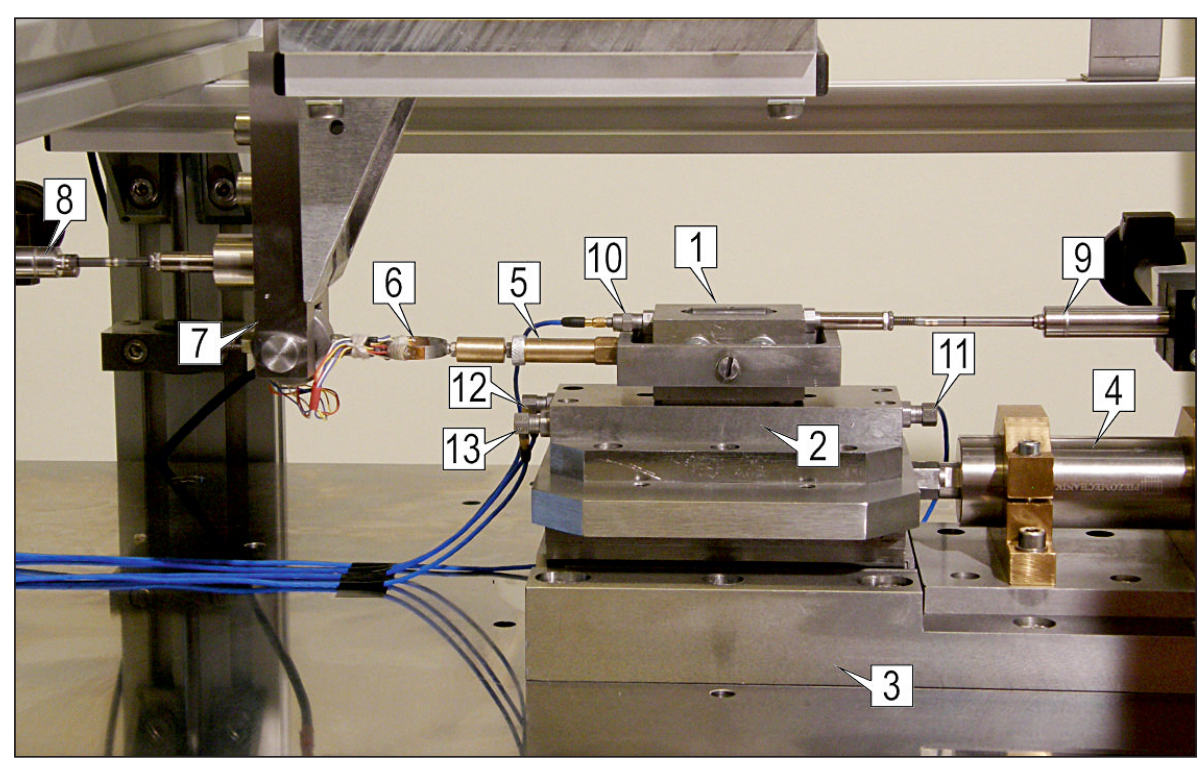

Fig. 5. A view of mechanical part of the test stand: 1 - upper specimen, 2 - lower specimen, 3 - fixed base, 4 - vibration exciter, 5 - drive stiffness adjustment system, 6 - ring dynamometer, 7 - carrier, 8, 9 - displacement transducers, 10-13 - accelerometers

pre-determined velocity $v_{d}$, and the lower specimen vibrates with a pre-determined frequency $f$ and amplitude of vibration velocity $v_{a}$.

The following data were assumed in numerical analyses and corresponding experimental tests: mass of the shifted body $m=0.665 \mathrm{~kg}$, external load $F_{Z}=29.4 \mathrm{~N}$, drive velocity $v_{d}=1 \mathrm{~mm} / \mathrm{s}$, stiffness coefficient of the drive system $k_{d}=11700 \mathrm{~N} / \mathrm{m}$ and frequency of forced vibrations $f=1500 \mathrm{~Hz}$.

The values of friction model's parameters adopted in numerical analyses are given in Table 1.
The selection of parameters and verification of Dahl and LuGre models were presented in detail in the papers of Gutowski and Leus [44] and Abrahamowicz, Gutowski and Leus [39]. Parameters for the Karnopp and the Reset Integrator models were assumed on the base of paper Heassing and Friedland [41]. The coefficient of static friction $\mu$ and the coefficient of contact stiffness $k_{t}$ was determined experimentally. The method of determining the coefficient has been described in detail in the papers of Leus and Gutowski [48]. 
Table 1. Adopted values of friction models parameters

\begin{tabular}{|c|c|}
\hline \multirow{3}{*}{ Dahl } & $k_{t}=71.318 \cdot 10^{6} \mathrm{~N} / \mathrm{m}$ \\
\hline & $\kappa=1$ \\
\hline & $F_{C}=8.3 \mathrm{~N}$ \\
\hline \multirow{3}{*}{ Karnopp } & $D V=0.01 \mathrm{~mm} / \mathrm{s}$ \\
\hline & $F_{S}=11.1 \mathrm{~N}$ \\
\hline & $F_{\text {slip }}=8.3 \mathrm{~N}$ \\
\hline \multirow{4}{*}{ Reset Integrator } & $k_{t}=71.318 \cdot 10^{6} \mathrm{~N} / \mathrm{m}$ \\
\hline & $\beta=4.869 \cdot 10^{3} \mathrm{Ns} / \mathrm{m}$ \\
\hline & $s_{0}=1.1 \cdot 10^{-4} \mathrm{~mm}$ \\
\hline & $a=0.34$ \\
\hline \multirow{6}{*}{ LuGre } & $k_{t}=71.318 \cdot 10^{6} \mathrm{~N} / \mathrm{m}$ \\
\hline & $h_{t}=1.377 \cdot 10^{4} \mathrm{Ns} / \mathrm{m}$ \\
\hline & $h_{V}=0 \mathrm{Ns} / \mathrm{m}$ \\
\hline & $F_{C}=8.3 \mathrm{~N}$ \\
\hline & $F_{S}=11.1 \mathrm{~N}$ \\
\hline & $v_{S}=3.5 \cdot 10^{-4} \mathrm{~m} / \mathrm{s}$ \\
\hline
\end{tabular}

Examples of the comparisons of drive force $F_{d}$ time characteristics determined numerically and experimentally are presented in Figs. 6-9. The Root Mean Square Error (RMSE) was used to compare the results of numerical calculations with results of experimental tests. The value of this coefficient was calculated from the formula:

$$
R M S E=\sqrt{\frac{1}{n} \sum_{i=1}^{n}\left(F_{d_{\mathrm{E}}}-F_{d_{\mathrm{M}}}\right)^{2}}
$$

where: $F_{d_{E}}$ - the driving force determined experimentally, $F_{d_{M}}$ - the driving force determined by model, $n-$ the numer of experimental points.

The RMSE values were calculated for the runs of driving force $F_{d}$ obtained in sliding motion, both on motionless (Fig. 6) and vibrating support (Fig. 7-9). The summary of the obtained Root Mean Squared Error values is presented in Table 2. The model for which the RMSE value was the lowest was considered the best model at given stage of movement.

In the first variant, which is illustrated in Figure 6, the upper specimen is shifted on motionless support - lower specimen. The presented comparisons of runs of the drive force indicate that in this case well consistency of the simulation and experimental results were obtained for three of the four friction models used in calculations, i.e. Karnopp model (Fig. 6.b), Reset Integrator model (Fig. 6.c) and LuGre model (Fig. 6.d). Mentioned models reflect the abrupt changes in drive force $F_{d}$ associated with the recurring cyclically phases in stick-slip movement. In contrast, the Dahl model (Fig. 6.a) does not show such behavior in time characteristics of drive force because it does not have mechanism for making the starting friction larger than the sliding friction [41]. In the analyzed motion without ground vibrations, the lowest RMSE value was obtained for the LuGre model.

In the second variant presented in Figs. 7-9, the sliding motion of upper specimen was carried out in two successive stages. In the first stage, the upper specimen was shifted on motionless support, while in the second stage the support was introduced into vibration. The presented time characteristics of drive force were obtained for three different values of vibration velocity amplitude $v_{a}$, i.e.: $v_{a_{1}}=0.2 \mathrm{~mm} / \mathrm{s}, v_{a_{2}}=1.1 \mathrm{~mm} / \mathrm{s}$ and $v_{a_{3}}=4 \mathrm{~mm} / \mathrm{s}$.

Figure 7 illustrates the runs determined for the first of the assumed amplitudes $v_{a_{1}}$, whose value was selected to be lower than the predetermined value of drive velocity $v_{d}$. Previous experimental studies conducted by the authors [36] indicate that the excitation of support vibrations parallel to the direction of sliding motion, in the range $v_{a}<v_{d}$, cause partial reduction of stick-slip phenomenon. It is manifested by a decrease in the amplitude of changes in the drive force, and thus a decrease in the amplitude of the abrupt jumps of

Table 2. Root Mean Squared Error between the measured and calculated $F_{d}$ for different models

\begin{tabular}{|c|c|c|}
\hline \multicolumn{3}{|c|}{ No vibrations } \\
\hline Figure & Model & $R M S E[\mathrm{~N}]$ \\
\hline \multirow{4}{*}{ Fig. 6.} & Dahl & 1.495 \\
\hline & Karnopp & 0.784 \\
\hline & Reset Integrator & 0.884 \\
\hline & LuGre & 0.778 \\
\hline \multicolumn{3}{|c|}{ With vibrations } \\
\hline Figure & Model & $R M S E[\mathrm{~N}]$ \\
\hline \multirow{4}{*}{ Fig. 7.} & Dahl & 1.139 \\
\hline & Karnopp & 1.052 \\
\hline & Reset Integrator & 0.405 \\
\hline & LuGre & 0.563 \\
\hline \multirow{4}{*}{ Fig. 8.} & Dahl & 0.142 \\
\hline & Karnopp & 0.335 \\
\hline & Reset Integrator & 0.135 \\
\hline & LuGre & 0.191 \\
\hline \multirow{4}{*}{ Fig. 9.} & Dahl & 0.650 \\
\hline & Karnopp & 0.532 \\
\hline & Reset Integrator & 0.471 \\
\hline & LuGre & 0.429 \\
\hline
\end{tabular}


the shifted body. The degree of reduction of the stick-slip increases as the amplitude $v_{a}$ increases.

In this range of $v_{a}$, the comparison of experimental and simulation results shows that the good consistency was obtained for Reset Integrator model (Fig. 7c) and the LuGre model (Fig. 7d). Indicated models ensure compliance of experimental and computational runs of drive force at both stages of shifting i.e. without and with support's vibrations, with a lower RMSE value obtained for the Reset Integrator model. When using in numerical analyses the Dahl friction model (Fig. 7a), the excitation of support vibration does not change the value of friction force. It remains constant, as it was in the first stage (Fig. 6a). Otherwise, using the Karnopp friction model (Fig. 7b), forced vibration causes a change in the run of drive force. This model demonstrates almost total reduction of the stick-slip phenomenon, which does not agree with the experimental results.

Total reduction of stick-slip movement occurs when the amplitude of vibration velocity $v_{a}$ is approximately equal or greater than the drive
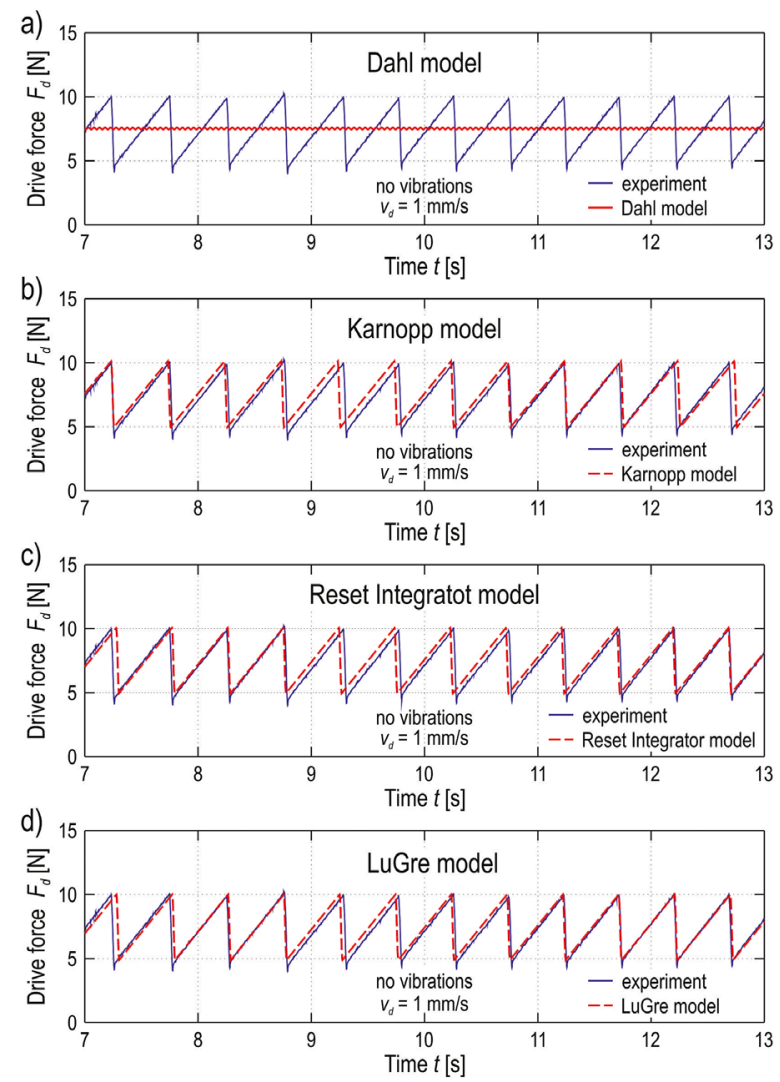

Fig. 6. Comparison of runs of the drive force $F_{d}$ for various friction models at motionless support: a) Dahl model, b) Karnopp model, c) Reset Integrator model, d) LuGre model; $v_{d}=1.0 \mathrm{~mm} / \mathrm{s}$ velocity $v_{d}$. This elimination is manifested by the sudden disappearance of abrupt changes in drive force, which are charateristic of stick-slip phenomenon. Increasing the amplitude $v_{a}$ above the value of velocity $v_{d}$ leads to a further reduction in the value of driving force $F_{d}$ necessary to initiate and maintain the sliding motion (Fig. 9).

Comparing the experimental and numerical runs presented in Figure 8 and Figure 9, it clearly seen that in range when $v_{a} \geq v_{d}$ Karnopp, Reset Integrator and LuGre ensure a qualitatively good compliance of the runs of driving force both in motion stage with and without supports vibrations. In the case shown in Figure 8, where there is complete stick-slip elimination, the lowest RMSE value was obtained for the Reset Integrator model. In turn, for the variant shown in Figure 9, with visible stage of reduction the driving force the lowest RMSE value was obtained for the LuGre model. Good compatibility, but only in the motion stage with forced vibration was also obtained for the Dahl model (Fig. 8a and Fig. 9a). In the papers of Leus and Gutowski [49] and Gutowski and Leus [44] it
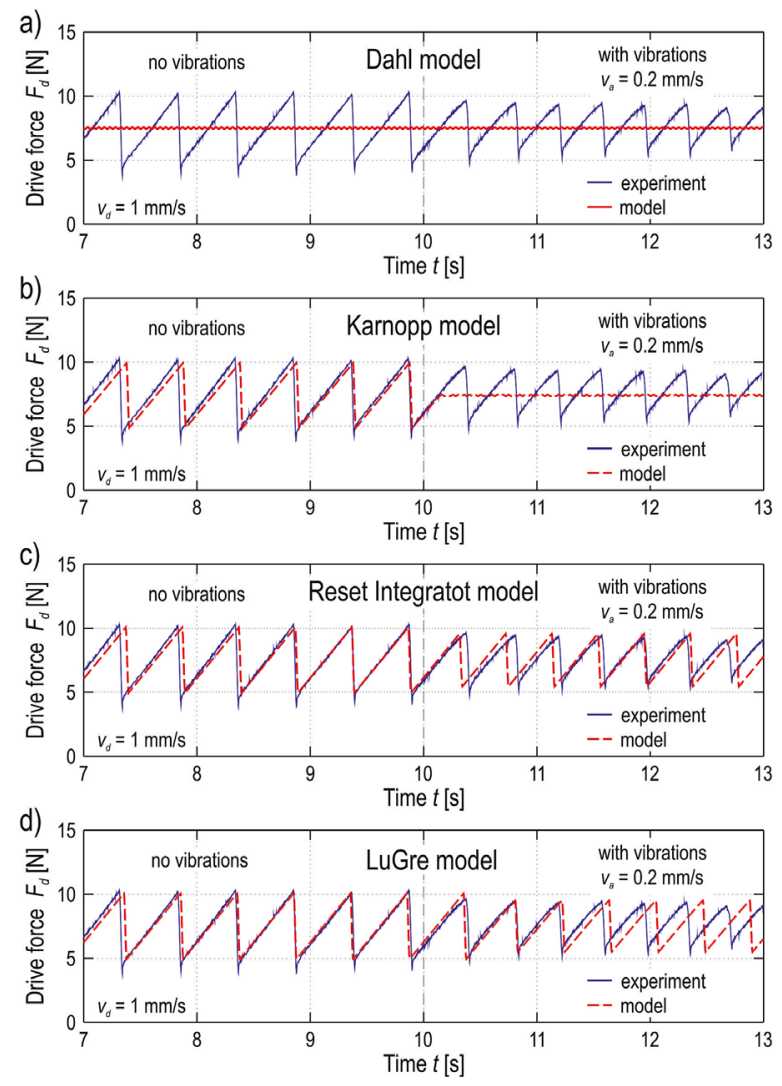

Fig. 7. Comparison of runs of the drive force $F_{d}$ for various friction models: a) Dahl model, b) Karnopp model, c) Reset Integrator model, d) LuGre model; $v_{d}=1.0 \mathrm{~mm} / \mathrm{s}, v_{a}=0.2 \mathrm{~mm} / \mathrm{s}, f=1500 \mathrm{~Hz}$ 
was shown that the Dahl friction model allows the accurately estimate the level of drive force reduction in sliding motion in the presence of longitudinal tangential vibrations. However, it is clearly seen from presented in this paper simulation and experimental results that it does not allow correct modeling of the stick-slip phenomenon.

\section{CONCLUSIONS}

Presented in the paper the numerical analyses and their experimental verification allow to assess which of the friction models is appropriate for modeling the stick-slip phenomenon and its partial or total reduction occurring as a result of the introduction of longitudinal tangential vibrations into the contact zone of friction pair. The studies carried out using the computational procedures developed in Matlab-Simulink environment indicate that the numerically obtained time characteristics of drive force clearly depend on the adopted friction model.
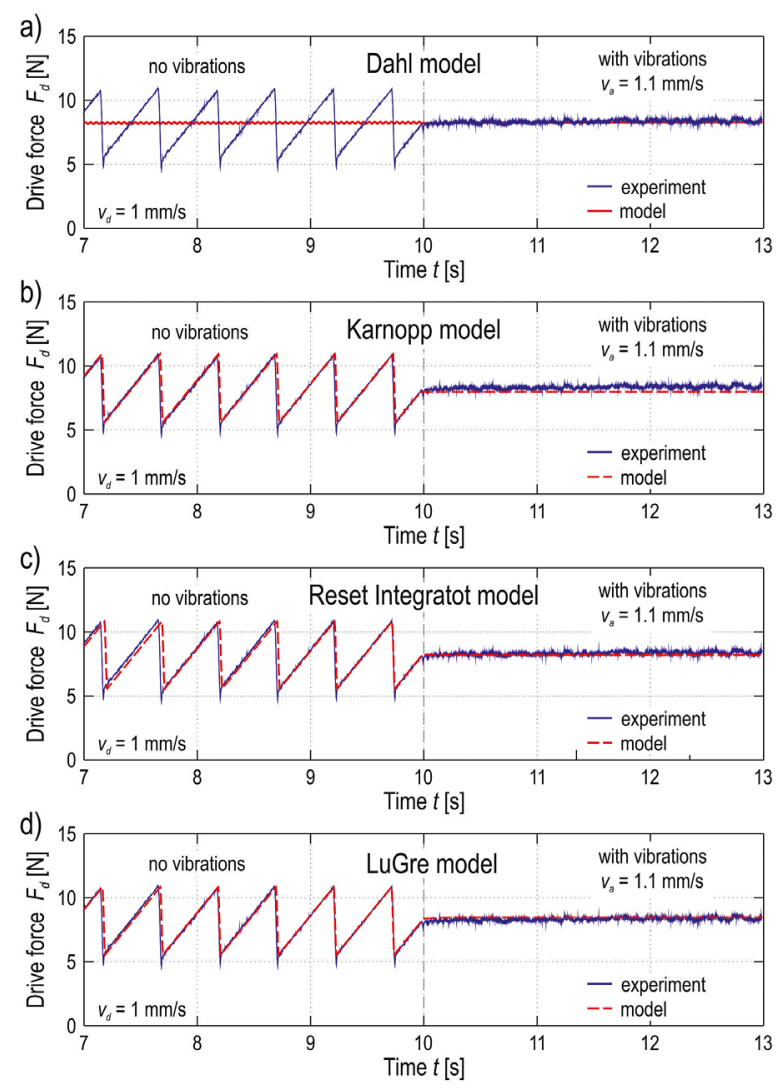

Fig. 8. Comparison of runs of the drive force $F_{d}$ for various friction models: a) Dahl model, b) Karnopp model, c) Reset Integrator model, d) LuGre model; $v_{d}=1.0 \mathrm{~mm} / \mathrm{s}, v_{a}=1.1 \mathrm{~mm} / \mathrm{s}, f=1500 \mathrm{~Hz}$
Analyses of numerical results using the Dahl model showed that this model is not able to reflect the stick-slip phenomenon. However, with this model, it is possible to predict the level of drive force reduction occurring after forcing longitudinal tangential vibrations with the amplitude of vibration velocity $v_{a}$ higher than the drive velocity $v_{d}\left(v_{a}>v_{d}\right)$.

The time characteristics of drive force, which were determined using the Karnopp model confirm that this model, according to its purpose, correctly reflects the stick-slip phenomenon. This model also well predicts the degree of reduction of the driving force under the influence of forced vibrations with the amplitude of vibration velocity $v_{a}$ greater than the given drive velocity $v_{d}\left(v_{a}>v_{d}\right)$. However, this model does not reflect a partial reduction of drive force under the influence of tangential longitudinal vibrations when $\left(v_{a}<v_{d}\right)$.

The best consistency of model and experimental time characteristics of the driving force was obtained for the Reset Integrator and the
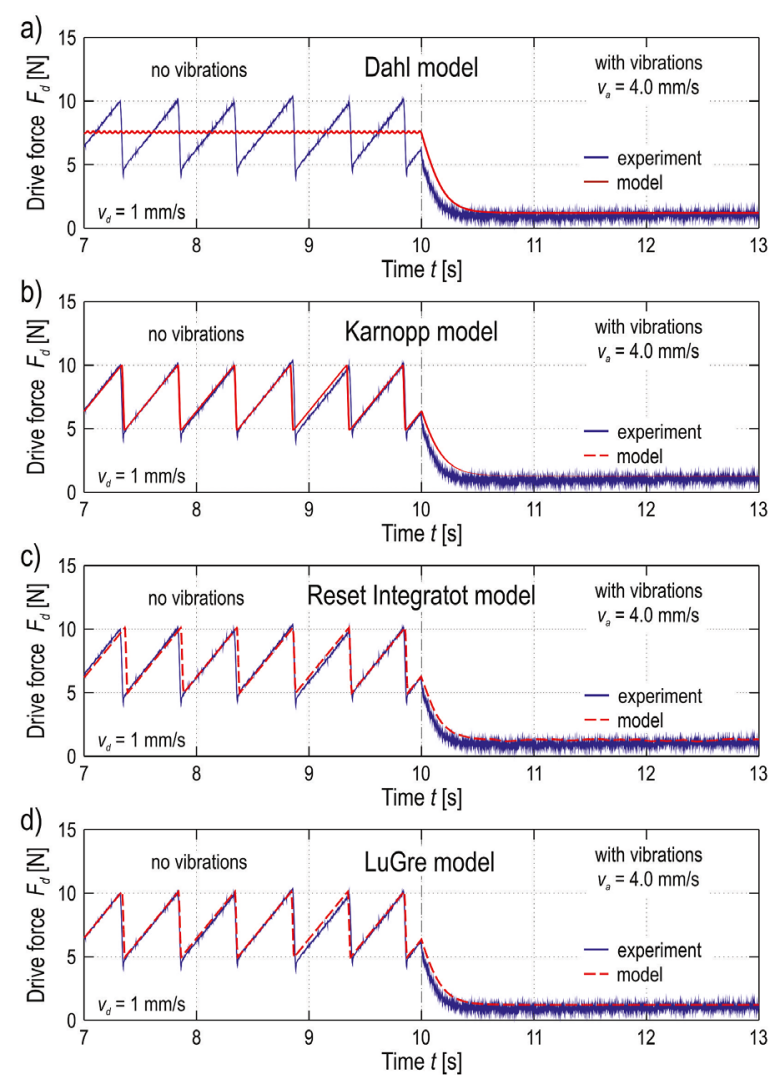

Fig. 9. Comparison of runs of the drive force $F_{d}$ for various friction models: a) Dahl model, b) Karnopp model, c) Reset Integrator model, d) LuGre model; $v_{d}=1.0 \mathrm{~mm} / \mathrm{s}, v_{a}=4.0 \mathrm{~mm} / \mathrm{s}, f=1500 \mathrm{~Hz}$ 
LuGre models. Excellent adjustment of these models to the results of experimental tests is obtained both in the variant of motion without support vibrations and in the presence of these vibrations. These models reflect both the stage of partial (when $v_{a}<v_{d}$ ) and total (when $v_{a}>v_{d}$ ) reduction of stick-slip vibrations.

\section{REFERENCES}

1. Johannes V., Green M., Brockley C. The role of the rate of application of the tangential force in determining the static friction coefficient. Wear. 1973;24(3):381-385.

2. Rabinowicz E. The nature of the static and kinetic coefficients offriction. Journal of Applied Physics. 1951;22(11):1373-1379.

3. Richardson R., Nolle H. Surface friction under time-dependent loads. Wear. 1976;37(1):87-101.

4. Courtney-Pratt J.S., Eisner E. The effect of a tangential force on the contact of metallic bodies. Proc. R. Soc. London, Ser. A. 1957;238(1215):529-550.

5. Armstrong-Helouvry B., Dupont P., Canudas de Witt C. A survey of models, analysis tools and compensation methods for the control of machines with friction. Automatica. 1994;30(7):1083-1138.

6. Kröger M., Neubauer M., Popp K. Experimental investigation on the avoidance of self-excited vibrations, Philosophical Transactions of The Royal Society A: Mathematical, Physical Engineering Science. 2008;366:785-810.

7. Wojewoda J., Stefański A., Wiercigroch M., Kapitaniak T. Hysteretic effects of dry friction: modelling and experimental studies, Philosophical Transactions of The Royal Society A: Mathematical, Physical Engineering Science. 2008;366:747-765.

8. Yanada H., SekikawaY. Modeling of dynamic behaviors of friction, Mechatronics. 2008;18(7):330-339.

9. Bell R., Burdekin M. A study of the stick-slip motion of machine tool feed drives. Proceedings of the Institution of Mechanical Engineers. 1969; 184(30):543-560.

10. Rabinowicz E. The intrinsic variables affecting the stick-slip process. Proceedings of the Physical Society. 1958;71(4):668-675.

11. Pennestrì E., Rossi V., Salvini P., Valentini P.P. Review and comparison of dry friction force models. Nonlinear Dynamics. 2016;83(4):1785-1801.

12. Nakano K., Maegawa S. Occurrence limit of stickslip: dimensionless analysis for fundamental design of robust-stable systems. Lubrication Science. 2010;22:1-18.

13. Tang L., Zhu X., Li J. Effects of the synchronous variation of the static and the kinetic friction coef- ficients on stick-slip vibration of drillstring. Iranian Journal of Science and Technology - Transactions of Mechanical Engineering. 2019;43:275-283.

14. Maegawa S., Itoigawa F. Design method for suppressing stick-slip using dynamic vibration absorber. Tribology International. 2019;140:1-8.

15. Mfoumou G.S., Kenmoé G.D., Kofané T.C. Computational algorithms of time series for stick-slip dynamics and time-delayed feedback control of chaos for a class of discontinuous friction systems. Mechanical Systems and Signal Processing. 2019;119:399-419.

16. Rymuza Z. The stick-slip phenomenon. PAK. 1992;12:290-295. (in Polish).

17. Qiu H., Yang J., Butt S. Investigation on bit stickslip vibration with random friction coefficients. Journal of Petroleum Science and Engineering. 2018;164:127-139.

18. Tang L., Zhu X., Shi C., Tang J., Xu D. Study of the influences of rotary table speed on stickslip vibration of the drilling system. Petroleum. 2015;1(4):382-387.

19. Sagert C., Di Meglio F., Krstic M., Rouchon P. Backstepping and flatness approaches for stabilization of the stick-slip phenomenon for drilling. IFAC Proceedings Volumes. 2013;46(2):779-784.

20. Saldivar B., Mondié S., Loiseau J.-J., Rasvan V. Stick-slip oscillations in oillwell drilstrings: distributed parameter and neutral type retarded model approaches. IFAC Proceedings Volumes. 2011;44(1):284-289.

21. F.Aarsnes U.J., Di Meglio F., Shor R.J. Avoiding stick-slip vibrations in drilling through startup trajectory design. Journal of Process Control. 2018;70:24-35.

22. Kamel J.M., Yigit A. Modeling and analysis of stick-slip and bit bounce in oil well drillstrings equipped with drag bits. Journal of Sound and Vibration. 333;2014:6885-6899.

23. Tang L., Zhu X., Qian X., Shi C. Effects of weight on bit on torsional stick-slip vibration of oilwell drill string. Journal of Mechanical Science and Technology. 2017;31(10):4589-4597.

24. Zhu X., Tang L., Yang Q. A literature review of approaches for stick-slip vibration suppression in oilwell drillstring. Advances in Mechanical Engineering. 2014;967952:1-17.

25. Kligerman Y., Varenberg M. Elimination of stickslip motion in sliding of split or rough surface. Tribology Letters. 53(2);2014:395-399.

26. Popp K., Rudolph M. Vibration control to avoid stick-slip motion, Journal of Vibration and Control. 2004;10:1585-1600.

27. Mokhtar M.O.A., Younes Y.K., El Mahdy T.H., Attia N.. A theoretical and experimental study on 
dynamics of sliding bodies with dry conformal contacts. Wear. 1998;218(2):172-178.

28. Abdo J., Tahat M., Abouelsoud A., Danish M. The effect of frequency of vibration and humidity on the stick-slip amplitude. International Journal of Mechanics and Materials in Design. 2010;6(1):45-51.

29. Abdo J., Zaier R. A novel pin-on-disk machine for stick-slip measurements. Materials and Manufacturing Processes. 2012;27:751-755.

30. Canudas de Witt C., Olsson H., Aström K.J., Lischinsky P. A new model for control of systems with friction. IEEE Transactions of Automatic Control. 1995;40(3):419-425.

31. Neubauer M., Neuber C-C., Popp K. Control of stick-slip vibrations. Solid Mechanics and its Applications. 2005;130:223-232.

32. Ozaki S., Hashiguchi K. Numerical analysis of stick-slip instability by a rate-dependent elastoplastic formulation for friction. Tribology International. 2010;43:2120-2133.

33. Zhang S.L., Valentine J.M. Stick-slip and temperature effect in the scratching of materials. Tribology Letters. 2002;12(4):195-202.

34. Zuleeg J. How to measure, prevent, and eliminate stick-slip and noise generation with lubricants, SAE Technical Paper. 2015;2015-01-2259:1-7.

35. Abdo J., Tahat M., Abouelsoud A. The effect of excitation frequencies on stick-slip amplitude, 3rd International Conference on Integrity, Reliability and Failure, Porto/Portugal 2009, 319-320.

36. Leus M., Abrahamowicz M. Experimental investigations of elimination the stick-slip phenomenon in the presence of longitudinal tangential vibration. Acta Mechanica et Automatica. 2019;13(1):45-50.

37. Popov V.L., Starcevic J., Filippov A.E. Influence of ultrasonic in-plane oscillations on static and sliding friction and intrinsic length scale of dry friction processes. Tribology Letters. 2010;39(1):25-30.

38. Popp K., Rudolph M. Avoidance of stick-slip motion by vibration control. Proceedings in Applied
Mathematics and Mechanics. 2003;3:120-121.

39. Rybkiewicz M., Gutowski P., Leus M. Experimental and numerical analysis of stick-slip suppression with the use of tangential vibration. Journal of Theoretical and Applied Mechanics (accepted for publication) 2020.

40. Teidelt E., Starcevic J., Popov V.L. Influence of ultrasonic oscillation on static and sliding friction. Tribology Letters. 2012;48(1):51-62.

41. Haessig Jr. D.A., Friedland B. On the Modeling and Simulation of Friction, Journal of Dynamic Systems, Measurement, and Control. 1991;113(3):354-362.

42. Liu Y.F., Li J., Zhang Z.M., Hu X.H., Zhang W.J. Experimental comparison of five friction models on the same test-bed of the micro stick-slip motion system. Mechanical Sciences. 2015;6(1):15-28.

43. Dahl P. Solid friction damping of mechanical vibrations. AIAA Journal. 1976;14(12):1675-82.

44. Gutowski P., Leus M. The effect of longitudinal tangential vibrations on friction and driving forces in sliding motion. Tribology International. 2012;55:108-118.

45. Karnopp D. Computer Simulation of Stick-Slip Friction in Mechanical Dynamic Systems. Journal of Dynamic Systems, Measurement, and Control. 1985;107(1):100-103.

46. Olsson H. Control systems with friction. Doctoral thesis. Department of Automatic Control. Lund Institute of Technology; 1996.

47. Bliman P.A. Mathematical study of the Dahl's friction model. European Journal of Mechanics, A/Solids. 1992;6:835-848.

48. Leus M., Gutowski P. The experimental analysis of the tangential stiffness of the flat contact joint. Modelling in Engineering. 2009;6(7):85-192.

49. Leus M., Gutowski P. Practical possibilities of utilization of tangential longitudinal vibrations for controlling the friction force and reduction of drive force in sliding motion. Mechanics and Mechanical Engineering. 2011;15(4):103-113. 